\title{
PD-L1 in Breast Cancers and its Prognostic Significance
}

\author{
Sayher Kazmi, Sumayyah Shawana, Nighat Jamal
}

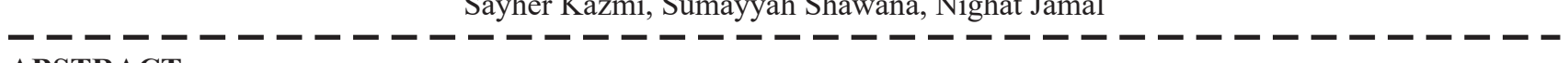
ABSTRACT:

Breast cancer is the most common malignancy in females globally. Various factors are responsible for its development which include both genetic and hormonal causes. An important discovery is the role of the PD-1/PD-L1 axis in the development of cancers. The PD-1-/PD-L1 pathway plays a part in allowing tumour cells escape from the host's immune response and hence permits the proliferation of tumour cells. PD-L1 expression has been observed in various breast cancers at distinct levels such as in tissues and in blood. Different methods have been utilized for its detection including immunohistochemistry, RNA sequencing and ELISA, amongst others. The results have been conflicting regarding the expression of PD-L1 and the prognosis of breast cancer based on parameters such as overall survival and disease free survival. Different immunotherapies have also emerged as a new modality to treat breast cancer. This review intends to explore the prognostic significance of PD-L1 expression in breast cancers.

Keywords: Breast cancer, PD-L1, Prognosis

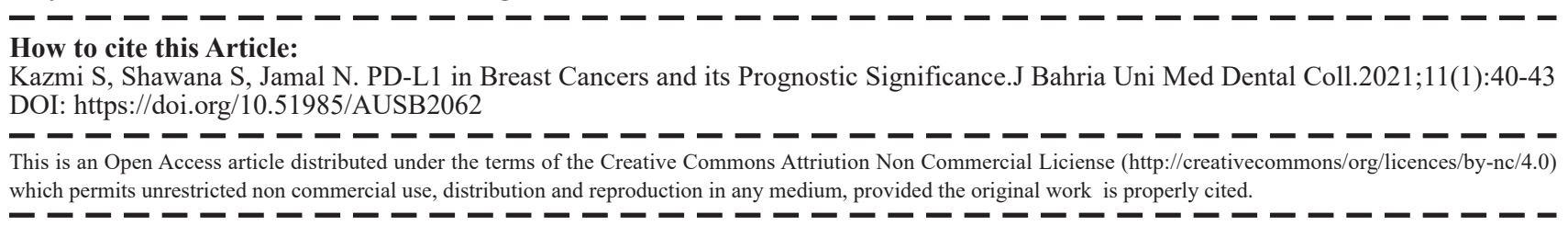

\section{INTRODUCTION:}

Breast cancer continues to be the leading malignancy in females worldwide. In 2018, the incidence of breast cancer was $2,088,849$, which consisted $11.6 \%$ of the total cancers in both genders combined. ${ }^{1}$ It is also the number one cancer reported in Pakistan amongst adults. ${ }^{1-2}$ It is a heterogeneous disease resulting from a mixture of genetics and hormonal interplay. Around $12 \%$ of breast cancers emerge because of a mutated gene inheritance. Mutations in the tumour suppressor genes such as BRCA1, BRCA2, TP53 and CHEK 2 are liable in the causation of familial cancers, the most common being BRCA 1 and BRCA2 mutations. The risk factors for harboring breast cancer include diet, hormonal changes (early menarche, late menopause) radiation exposure, having a first degree relative with breast cancer and genetics. ${ }^{3}$ Breast cancer can be divided according to its histological status and molecular subtypes, which include Luminal A, Luminal B, HER2 enriched and triple negative. ${ }^{3-5}$

Over the years the PD1/PDL1 pathway has gained enormous attention for the role it plays in tumour immune escape. ${ }^{6}$ PD-1, also known as CD 279, was originally cloned in 1992,

\begin{tabular}{|c|}
\hline $\begin{array}{l}\text { Sayher Kazmi (M. Phil Student) } \\
\text { Department of Pathology, } \\
\text { Bahria University Medical and Dental College, Karachi } \\
\text { Email: kazmi.s@hotmail.com }\end{array}$ \\
\hline $\begin{array}{l}\text { Sumayyah Shawana } \\
\text { Associate Professor, Department of Pathology } \\
\text { Bahria University Medical and Dental College, Karachi }\end{array}$ \\
\hline $\begin{array}{l}\text { Nighat Jamal } \\
\text { Assistant Professor, Classified Pathologist } \\
\text { PNS Shifa Hospital, Karachi }\end{array}$ \\
\hline $\begin{array}{l}\text { Received: } 10-F e b-2020 \\
\text { Accepted: 09-Sep-2020 }\end{array}$ \\
\hline
\end{tabular}

and was primarily thought to be a part of the apoptotic pathway of cells ${ }^{7}$. It is a receptor located on T cells. ${ }^{8} \mathrm{PD}-$ $\mathrm{L} 1$, also known as B7-H1, is the ligand of PD-1. ${ }^{9}$ Alongside being found on macrophages, dendritic cells and B cells, it is expressed on malignant cells. ${ }^{8}$ The interaction of PD-1 and PD-L1 causes increased apoptosis of T cells, thus cancer cells have a route of evading the immune system. ${ }^{10}$ It has been extensively studied that along with many other cancers, breast cancer cells overexpress the PD-L1 receptor. ${ }^{11-17}$ PDL1 has been found to be expressed in renal cell carcinomas, ${ }^{11}$ non-small cell lung carcinomas, ${ }^{12}$ colorectal carcinomas, ${ }^{13}$ ovarian carcinomas ${ }^{14}$ and melanomas. ${ }^{15}$

Prognosis can be defined as "the prospect of recovery as anticipated from the usual course of disease or peculiarities of the case" ${ }^{18}$. Prognosis in breast cancers is largely determined by the clinicopathological parameters. These include age, gender, tumor size, lymph node metastasis, lymphovascular invasion, neural invasion ${ }^{19}$, histologic subtype, grade, stage, mitotic figure count and hormone receptor status. ${ }^{20}$ High expression or overexpression of PDL1 can also influence prognosis as reviewed.

\section{METHODOLOGY:}

A methodically comprehensive search was performed using NCBI PubMed database and Google Scholar. 73 relevant articles from the years 2000 to 2019 were found from this literature search. The studies were scrutinized and evaluated further for the magnitude and significance of breast cancer, and the prognostic value of PD-L1. Out of these articles, 50 were ultimately selected. Articles which were unrelated to the topic and obsolete texts were excluded. Based on these criteria, this review article was devised. 


\section{Literature review:}

The city of Karachi, Pakistan, is stated to have the topmost incidence of breast cancer in Asian populations, excluding Israeli Jews. The reasons for this are not all entirely obvious, however, certain risk factors make the women more vulnerable to harboring it. It also accounts for one third of all female cancers. ${ }^{21}$ In the United States and Europe, breast cancer incidence rate is four to seven times higher as compared to other countries, but since developing countries are implementing Western lifestyles, such as decreased breastfeeding and fewer number of pregnancies, it is predicted that by this year, 2020, 70\% of breast cancer cases would be found in the developing countries. ${ }^{3}$

The PD-1 and PD-L1 combination is an immune checkpoint. Working together, they prevent cytotoxic $\mathrm{T}$ cells from performing an excess of their function, thus maintaining a steady state of $\mathrm{T}$ cell function and preventing over stimulation. However, tumor cells can take advantage of this route by expressing PD-L1 themselves, hence avoiding the immune system and proliferating. ${ }^{22}$

PD-L1 expresses in a variety of forms in different regions. It is seen in tissues, where it can be detected as protein ${ }^{23}$ or $\mathrm{mRNA}^{24}$. Current evidence has shown that the membrane bound PD-1 and PD-L1 have circulating forms as well and hence may be detected in blood in the soluble form ${ }^{25,26}$ or as exosomes ${ }^{27}$.

Consequently, there are a variety of methods and procedures for its detection which include immunohistochemistry (IHC), flow cytometry \& ELISA, in situ hybridization, PCR, DNA microarrays and RNA sequencing ${ }^{28-33}$. There is currently no set standard for the evaluation and expression of PD-L1 and many challenges exist. PD-L1 expression had initially been determined through IHC in tumours but detection through IHC comes with its own share of limitations. Some include differences in antibody clones of different companies, the method used to score the variables, and the small innate differences in PD-L1 expression in the different types of specimens like surgical resection and biopsies, fresh frozen and archives, and primary and metastatic tumours ${ }^{34-35}$. Besides $\mathrm{IHC}$, analysis at the protein or messenger RNA level have different cells involved in expression such as tumour cells or tumour infiltrating lymphocytes. Hence the availability and utilization of different techniques may be responsible for the differing results in literature ${ }^{36}$.

Prognosis is usually based on various parameters which includes overall survival, when the cause of death is not specified; disease free survival, the time period after treatment when no disease, or cancer, can be identified; and metastasis free survival, defined as the time from the start of treatment for cancer in which the patient is alive with no metastasis. ${ }^{37}$ PD-L1 can be used as a prognostic marker in breast cancer, however, the relationship among overall survival, clinicopathological features and prognosis in general amongst breast cancer patients is conflicting.

Several commentaries have suggested that expression of PD-L1 in breast cancer patients can be a favorable prognostic marker ${ }^{17,38-40}$. It has been linked to negative lymph node metastasis and an increased tumour infiltrating lymphocyte count, leading to a better overall survival ${ }^{17}$ and disease free survival. ${ }^{17,38}$.Cytoplasmic expression of PD-L1 in tumour cells is associated with a lower risk of breast cancer specific deaths, and both PD-L1 expression and tumour infiltrating lymphocyte count are related to a better outcome ${ }^{39}$.

Amongst the subsets of breast cancers, PD-L1 is seen to be more significantly expressed in the triple negative group or basal like tumors ${ }^{28}$, and in this subcategory, PD-L1 expression is associated with a favorable prognosis due to a better disease free survival. ${ }^{38}$ It has also been observed that PDL1 expression, when linked to poor prognostic features such as high tumour grade, was associated with a good relapse free survival specifically in the basal type, and not with the outcome of breast cancers in general $^{40}$. Remarkably, PD-L1 expression has led to a better overall survival in some breast cancer cases which presented with poor clinicopathological features, probably due to an anti tumour response ${ }^{16,41}$. The expression of PD-L1 has also been reported to activate immune-related pathways such as IFN á, IFN ã and TNF á, hence leading to a good prognosis and it seems to be the only prognostic element in metastasis free survival ${ }^{42}$.

Some evidence has concluded an opposing relationship regarding PD-L1 expression in breast cancer and prognosis, with its expression being associated with a poor overall survival and an independent negative prognostic factor ${ }^{43}$. Higher PD-L1 expression has also been observed in patients who were younger than 35 , who presented at an advanced stage and those with a larger tumour size and hence are linked with a poor disease free and overall survival ${ }^{44}$. A meta-analysis which comprised of 5 studies and a total of 2546 breast cancer patients also showed a link between PDL1 expression and a reduced overall survival ${ }^{45}$. PD-L1 expression is a poor prognostic marker in those triple negative breast cancers which have a low tumour infiltrating lymphocyte count. ${ }^{46}$

Along with the traditional treatments of chemotherapy and radiotherapy for breast cancers, immunotherapies are also emerging which have encouraging results. ${ }^{47}$ Drugs targeting PD-1 or PD-L1 have been discovered to improve the outcome of the patients; these drugs include Pembrolizumab, Atezolizumab, Avelumab and Nivolumab ${ }^{48}$. According to a review study, 500 studies were carried out on anti PD-1 and anti PD-L1, using nine types of antibodies from at least 8 pharmaceutical companies, on approximately 20 types of hematological and solid malignant tumors. ${ }^{49}$ This study further mentioned that some of the anti PD-1 and anti PDL1 drugs have already been permitted by the US Food and Drug Administration (FDA). Trials conducted have shown 
that these drugs, when used alone, may enhance a more favorable prognosis, and when they are used in combination with other drugs such as chemotherapeutics, the response is strengthened. ${ }^{50}$ Since there are conflicting results in literature regarding the prognostic significance of PD-L1 in breast cancers, and because very scarce data is available in Pakistan as well in this regard, there is a dire need for conducting further researches and clinical trials in this domain to gain coherent results. Doing so, the results will eventually aid in the selection of proper immunotherapeutic drugs for the treatment of breast cancer, alongside the existing therapies.

\section{CONCLUSION:}

Breast cancer continues to rank number one across the globe. Researches have demonstrated conflicting results regarding the expression of PD-L1 as an indicator of prognosis of breast cancer; which strongly supports the intense need of globally standardizing the detections methods \& techniques, cut off values, scoring systems and sample sizes for obtaining consistent results. A finding revealed in most studies is that PD-L1 expression may be a good prognosis of breast cancer if it is associated with an increased tumour infiltrating lymphocyte count. This outcome may be due to the fact that increased PD-L1 expression causes a compensatory reaction of additional tumour infiltrating lymphocytes, which in turn provide the anti- tumour response, hence leading to a good prognosis. More research is warranted in this domain. Since plenty of research has also led to the conclusion that PDL1 expression is a poor prognostic marker in breast cancer as well, anti- PD-1/PD L1 therapy is gaining momentum and is an encouraging breakthrough for treatment of breast cancer. Further studies and clinical trials are needed in this regard to evaluate the effect of immunotherapeutic drugs on breast cancers.

Г - - - - - - - - - - - - - - - Sayher Kazmi: Conceiving the idea, literature search,
| writing of the article

| Sumayyah Shawana: Literature review, critical analysis of I article

Nighat Jamal: Critical review of article

L ----------------

REFERENCES:

1. Bray F, Ferlay J, Soerjomataram I, Siegel RL, Torre LA, Jemal A. Global Cancer Statistics 2018: GLOBOCAN estimates of incidence and mortality worldwide for 36 cancers in 185 countries. CA Cancer J Clin. 2018; 68(6):394-424.

2. Yousaf A, Mahmood S, Faraz R, Quader UA, Asif H, Atif A, et al . Annual Cancer Registry Report-2018, of the Shaukat Khanum Memorial Cancer Hospital \& Research Center, Pakistan. 2018 (cited July 2019). pp 4-8. Available at https://shaukatkhanum.org.pk/wp-content/uploads /2019/07/acrr-2018.pdf

3. Lester S, Kumar V, Abbas AK, Aster JC. The Breast. Robbins and Cotran Pathologic Basis of Disease. 9the Elsevier 2015 1052-1070.

4. Goldblum JR, McKenney JK, Lamps LW, Myers JL. Breast. Rosai and Ackerman's Surgical Pathology. 11the Elsevier; 2018 p 1492-1497
5. Perou CM, Sorlie T, Eisen MB, Rijn MV, Jeffrey SS, Rees $\mathrm{CA}$, et al. Molecular portraits of human breast tumours. Nature 2000: 406 (6797);747-752

6. Jiang X, Wang J, Deng X ,Xiong F, Ge J, Xiang B, et al. Role of the tumor microenvironment in PDL1/PD-1-mediated tumor immune escape. . Molecular Cancer 2019. 18 (10) https://doi.org/10.1186/s12943-018-0928-4

7. Ishida Y, Agata Y, Shibahara K, Honjo T. Induced expression of PD-1, a novel member of the immunoglobulin gene superfamily, upon programmed cell death. EMBO J. 1992 Nov;11 (11):3887-95.

8. Yamazaki T, Akiba H, Iwai H, Matsuda H, Aoki M, Tanno Y, et al. Expression of programmed death 1 ligands by murine $\mathrm{T}$ cells and APC. J Immunol. 2002; 169: 5538-45

9. Dong H, Zhu G, Tamada K, Chen L. B7-H1, a third member of the B7 family, co-stimulates T-cell proliferation and interleukin-10 secretion. Nat. Med. 1999, 5 (12): 1365-9. doi:10.1038/70932

10. Dong H, Strome SE, Salomao DR, Hideto T, Hirano F, Flies DB, et al. Tumour associated B7-H1 promotes T cell apoptosis: A potential mechanism of immune evasion. Nat. Med 2002. $8793-800$

11. Callea M, Albiges L, Gupta M, Cheng CS, Genega ME, Fay PA, et al. Differential Expression of PD-L1 between Primary and Metastatic Sites in Clear-Cell Renal Cell Carcinoma. Cancer Immunol. Res. 2015. 3(10) 1158-1164 doi: 10.1158/2326-6066

12. Rashed HE, AbdelRahman AE, AbdelGawad M, Balata S, El Shabrawy M. Prognostic Significance of Programmed Cell Death Ligand 1 (PD-L1), CD8+ Tumour Infiltrating Lymphocytes and p53 in Non Small Cell Lung Cancer: An Immunohistochemical Study. Turkish Journal of Pathology 2017; 33 (3) 211-222. doi: 10.5146/tjpath.2017.01398

13. Liu S, Gonen M, Stadler ZK, Weiser MR, Hechtman JF, Vakiani E, et al. Cellular localization of PD-L1 expression in mismatch-repair deficient and proficient colorectal carcinomas. Modern Pathol. 2018; 32; 110-121. doi https://doi.org/ 10.1038 /s41379-018-0114-7.

14. Gottlieb CE, Mills MA, Cross VJ, Ring LK . Tumor-associated macrophage expression of PD-L1 in implants of high grade serous ovarian carcinoma: A comparison of matched primary and metastatic tumors. Gynecol. Oncol 2016 144(3) 607-612. doi http://dx.doi.org/10.1016/j.ygyno.2016.12.021

15. Thiem A, Hesbacher S, Kneitz H, di Primio T, Heppt MV, Hermanns HM, et al. IFN-gamma-induced PD-L1 expression in melanoma depends on p53 expression. J. Exp. Clin. Cancer Res. 2019: 38(1) 397-415 doi:10.1186/s13046-019-1403-9

16. Hou Y, Nitta H, Wei L, Banks MP, Lustberg M, Wesolowski $\mathrm{R}$, et al. PD-L1 expression and CD8-positive T cells are associated with favorable survival in HER2-positive invasive breast cancer. Breast J. 2018; 0:911-919. Doi: 10.1111/ tbj. 13112

17. Bae SB, Cho HD, Oh MH, Lee JH, Jang SH, Hong SA, et al. Expression of Programmed Death Receptor Ligand 1 with High Tumour Infiltrating Lymphocytes is Associated with Better Prognosis in Breast Cancer. J Breast Cancer 2016 19(3) 242-251. doi: 10.4048/jbc.2016.19.3.242

18. Prognosis. In: The Merriam-Webster.com Dictionary (Internet) Merriam-Webster Inc. (cited 14-01-2010) Available from https://www.merriam-webster.com/dictionary/prognosis

19. Lei YY, Huang J, Zhao Q, Jiang N, Xu H, Wang Z et al. The clinicopathological parameters and prognostic significance of HER2 expression in gastric cancer patients: a meta-analysis of literature. World J Surg Oncol. 201715 (68). Doi 10.1186 /s12957 -017-1132-5 
20. Fitzgibbons PL, David LP, Weaver D, Thor AD, Allred C, Clark GM, et al. Prognostic factors in breast cancer. Arch Pathol Lab Med 2000; 124 (7): 966-978

21. Bhurgri Y, Bhurgri A, Hassan SH, Zaidi SH, Rahim A, Sankaranarayanan $\mathrm{R}$ et al. Cancer Incidence in Karachi, Pakistan: First Results from Karachi Cancer Registry. Int. J. Cancer $2000: 85,325-329$

22. Soysal SD, Tzankov A, Muenst SE. Role of the Tumor Microenvironment in Breast Cancer. Pathobiology 2015; 82(3-4):142-52. doi:10.1159/000430499.

23. Rittmeyer A, Barlesi F, Waterkamp D, Park K, Ciardiello F, Von PJ, et al. Atezolizumab versus docetaxel in patients with previously treated nonsmall-cell lung cancer (OAK): a phase 3 , openlabel, multicentre randomised controlled trial. Lancet 2016;387:1837.

24. Duncan DJ, Scott M, Scorer P, Barker C. Assessment of PDL1 mRNA and protein expression in non-small cell lung cancer, head and neck squamous cell carcinoma and urothelial carcinoma tissue specimens using RNAScope and immunohistochemistry. PloS One. 2019 14(4): e 0215393 112 doi: 10.1371/journal.pone.0215393

25. Nagato T, Ohkuri T, Ohara K, Hirata Y, Kishibe K, Komabayashi Y, et al. Programmed death-ligand 1 and its soluble form are highly expressed in nasal natural killer/Tcell lymphoma: a potential rationale for immunotherapy. Cancer Immunol Immunother 2017;66:877-90

26. Zhou J, Mahoney KM, Giobbie-Hurder A, Zhao F, Lee S, Liao X, et al. Soluble PD-L1 as a Biomarker in Malignant Melanoma Treated with Checkpoint Blockade. Cancer Immunol Res. 2017;5(6):480-492. doi: 10.1158/2326-6066

27. Theodoraki MN, Yerneni S, Hoffmann TK, Gooding WE, Whiteside TL. Clinical significance of PD-L1+ exosomes in plasma of head and neck cancer patients. Clin Cancer Res. 2018; 24:896-905

28. Soliman H, Khalil F, Antonia S. PD-L1 Expression is Increased in a subset of Basal Type Breast Cancer Cells. PLOS One $20149(2)$ e 88575 https://doi.org/10.1371/ journal.pone. 0088557

29. Gatalica Z, Snyder C, Maney T, Ghazalpour A, Holterman $\mathrm{D}$, Xiao $\mathrm{N}$ et al. Programmed Cell Death 1 (PD-1) and Its Ligand (PD-L1) in Common Cancers and Their Correlation with Molecular Cancer Type. Cancer Epidemiol Biomarkers 2014; 23(12): 2965-2970. doi: 10.1158/1055-9965

30. Li Z, Dong P, Ren M, Song Y, Qian X, Yang Y, et al. PD-L1 Expression Is Associated with Tumor FOXP3+Regulatory TCell Infiltration of Breast Cancer and Poor Prognosis of Patient J Cancer. 2016;7(7):784-793 doi:10.7150/jca.14549

31. Yuan J, Zhang J, Zhu Y, Li N, Tian T, Li Y, et al. Programmed death-ligand-1 expression in advanced gastric cancer detected with RNA in situ hybridization and its clinical significance. Oncotarget 2016. 7:39671-39679

32. Okuma Y, Hosomi Y, Nakahara Y, Watanabe K, Sagawa Y, Homma S. High plasma levels of soluble programmed cell death ligand 1 are prognostic for reduced survival in advanced lung cancer. Lung Cancer 2017;104:1-6. Doi 10.1016/j. lungcan.2016.11.023

33. Uhercik M, Sanders AJ, Owen S, Davies EL, Sharma AK, Jiang WG, et al. Clinical Significance of PD1 and PDL1 in Human Breast Cancer. Anticancer Res. 2017;37(8):4249-54

34. Pinato DJ, Shiner RJ, White SD, Black JR, Trivedi P, Stebbing $\mathrm{J}$, et al. Intra-tumoral heterogeneity in the expression of programmed-death (PD) ligands in isogeneic primary and metastatic lung cancer: Implications for immunotherapy. Oncoimmunology 2016.;5(9) 1213934 1-7
35. Patel SP, Kurzrock R. PD-L1 expression as a predictive biomarker in cancer immunotherapy. Mol Cancer Ther 2015;14:847-56

36. Kwa MJ, Adams S. Checkpoint inhibitors in triple-negative breast cancer (TNBC): Where to go from here. ACS Journals Cancer 2018; 124 (10): 2086-2103

37. NCI dictionary of cancer terms- National Cancer Institute.(Internet) (cited 16-01-2020.) Available from https://www.cancer.gov/publications/dictionaries/cancer-terms

38. Botti G, Collina F, Scognamiglio G, Rao F, Peluso V, DeCecio $\mathrm{R}$, et al. Programmed death ligand 1 (PD-L1) tumor expression is associated with a better prognosis and diabetic disease in triple negative breast cancer patients. Int. J. Mol. Sci. 2017; 18(2): 459- 469. https://doi.org/10.3390/ijms18020459

39. Beckers RK, Selinger CI, Vilain R, Madore J, Wilmott JS, Harvey K, et al. Programmed death ligand 1 expression in triple-negative breast cancer is associated with tumourinfiltrating lymphocytes and improved outcome. Histopathology 2016; 69: 25-34. DOI: 10.1111/his.12904

40. Wang ZQ, Milne K, Derocher H, Webb JR, Nelson BH, Watson PH. PD-L1 and intratumoral immune response in breast cancer. Oncotarget 2017; 8: 51641-51651.

41. Baptista MZ, Sarian LO, Derchain SF, Pinto GA, Vassallo J. Prognostic significance of PD-L1 and PD-L2 in breast cancer. Human Pathology 2015;47(1): 78-84. http://dx.doi.org/ 10.1016/j.humpath.2015.09.006.

42. Sabatier R, Finetti P, Mamessier E, Adelaide J, Chaffanet M, Ali $\mathrm{H}$, et al. Prognostic and predictive value of PDL1 expression in breast cancer. Oncotarget 2015 6(7), 5449-5464

43. Muenst S, Schaerli AR, Gao F, Däster S, Trella E, Droeser RA, et al. Expression of programmed death ligand 1 (PD-L1) is associated with poor prognosis in human breast cancer. Breast Cancer Res Treat. 2014;146(1):15-24.

44. Qin T, Zeng YD, Qin, G, Xu F, Lu JB, Fang WF, et al. High PD-L1 expression was associated with poor prognosis in 870 Chinese patients with breast cancer. Oncotarget 2015; 6(32): 33972-33981. doi:10.18632/oncotarget.5583

45. Zhang M, Sun H, Zhao S, Wang Y, Pu H, Wang Y, et al. Expression of PD-L1 and prognosis in breast cancer: a metaanalysis. Oncotarget 2017;8(19):31347-31354.

46. Mori H, Kubo M, Yamaguchi R, Nishimura R, Osako T, Arima $\mathrm{N}$ et al. The combination of PD-L1 expression and decreased tumor-infiltrating lymphocytes is associated with a poor prognosis in triple-negative breast cancer. Oncotarget 2017;8(9):15584-15592.

47. Cruz LM, Czerniecki BJ. Immunotherapy for Breast Cancer is Finally at the Doorstep: Immunotherapy in Breast Cancer. Ann Surg Oncol 2018; 25(10):2852-2857

48. Planes GL, Rochigneux P, Bertucci F, Chrétien AS, Viens P, Sabatier R, et al. PD-1/PD-L1 Targeting in Breast Cancer: The First Clinical Evidences Are Emerging. A Literature Review. Cancers (Basel) 2019; 11(7):1033-1058.

49. Iwai Y, Hamanishi J, Chamoto K, Honjo T. Cancer immunotherapies targeting the PD-1 signaling pathway. J Biomed Sci. 2017; 24(1):26-37. doi: 10.1186/s12929-0170329-9

50. Schmid P, Park Y, Muñoz-Couselo C, Kim SB, Sohn J, Im $\mathrm{SA}$, et al. Pembrolizumab plus chemotherapy as neoadjuvant treatment of high- risk, early- stage triple negative breast cancer: results from the Phase $1 \mathrm{~b}$ open- label multicohort KEYNOTE 173 study. Ann Oncology 2020; 31(5): 569-581 